\title{
Variety of responses and reactive inhibition'
}

\author{
Dixie M. Nohara 2 \\ NORTHWESTERN UNIVERSITY
}

\begin{abstract}
Abstraet
This experiment involved four lengths of intertrial interval $(0,5,20$, or $60 \mathrm{sec}$.) and four numbers of different letters $(1,3,5$, or 7$)$ to be written over and over again during 101 -min.trials. Increasing either the length of the interval or the number of different letters produced significantly higher performances (measured by the number of letters written per trial), but the predicted interaction was not significant.
\end{abstract}

\section{Introduetion}

This experiment stemmed from a study by Robinson \& Bills (1926) in which Ss wrote either two or six different letters over and over again for $20 \mathrm{~min}$. A greater work decrement resulted with two letters than with six, and this difference was attributed to the greater homogeneity of the two-letter condition. Along the lines of more recent thinking, the work decrement might be attributed to the accumulation of reactive inhibition $\left(\mathrm{I}_{R}\right)$. In the extreme case, $\mathrm{I}_{\mathbf{R}}$ might be specific to each letter written. Still in keeping with the current conception of $I_{R}$, it is expected that $I_{R}$ will dissipate with rest. If $I_{R}$ is specific to each letter, resting might come about in two ways. One is that $\mathrm{S}$, while writing a particular letter, may be resting from writing others; the $I_{R}$ accumulated while $S$ writes one particular letter might dissipate while he writes other letters. It follows that the total amount of $I_{R}$ accumulated for a given letter would grow less and less as the number of different letters increased; therefore, the total amount of $I_{R}$ accumulated for a given work period would decrease as the number of different letters increased. The second opportunity for resting would occur if $\mathrm{E}$ inserted a rest interval between trials. If there is greater accumulation of $I_{R}$ with fewer than with more letters, performance on a few letters (where the greatest amount of $I_{R}$ would build up) should benefit more from a rest period than performance on a larger number of letters. Thus, an interaction between interval and letters would be expected.

The purpose of this experiment was to test these hypotheses: (1) groups writing several different letters over and over would perform at a higher level (write more letters per trial) than groups writing only one letter, (2) groups with a long intertrial interval should perform at a higher level than those with shorter intervals, and (3) interval and letters should interact, with groups with fewer letters benefitting more from a long rest period.

\section{Method}

A factorial design with four lengths of intertrial interval $(0,5,20$, or 60 sec.) and four numbers of different letters $(1,3,5$, or 7$)$ to be written was used.
Two hundred eighty-eight introductory psychology students were divided equally among the 16 groups. They were run in groups of 20 and assigned to conditions in the order in which they came to the laboratory. The specific letter combinations were a, b, c, d, e, f, or $g$ for the one-letter conditions; abc, bcd, cde, def, or efg for the three-letter conditions; abcde, bcdef, or cdefg, for the five-letter conditions; and abcdefg for the sevenletter conditions. Each letter or letter combination was used an approximately equal number of times. Each group was given $101-\mathrm{min}$. trials, and all $\mathrm{Ss}$ in a given group had the same intertrial interval but different numbers of letters to write. The groups will subsequently be designated by two numbers, the first indicating the interval and the second indicating the number of letters for that group (e. g., 0-7 refers to the group which had no time between trials and seven letters to write).

Examination booklets were used to collect the data, with the particular letter combination which each $S$ was to write being written on the first page of his booklet. At the beginning of each trial, E said "Go," and the Ss began writing their letter or letters over and over again as rapidly as possible. At the end of each trial, E said "Mark," and each S drew a vertical line on his page in place of the next letter he would have written and waited until $\mathrm{E}$ again said "Go" before he resumed writing. The vertical mark indicated the end of each trial on each S's record.

\section{Results}

To illustrate the course of performance, the mean number of letters written on each trial for the two extreme letter conditions within the two extreme interval conditions (groups $0-1,0-7,60-1$, and 60-7) is shown in Fig. 1. These curves indicate work decrement with the 0 intervals, increases in performance with the 60-sec. intervals, and a difference between the number of letters written for the one-letter groups vs. the seven-letter groups. No further analysis was made of these data in this form, but an analysis of variance was computed over the total number of letters written by each group. As the number of different letters to be written increased, the total number of letters written increased $(F=23.08 ;$ df $3 / 272 ; p<.01)$, and as the length of the intertrial interval increased, more letters were written $(F=7.47 ;$ df $3 / 272 ; p<.01)$. The letters $\mathbf{x}$ interval interaction was not significant. An analysis of variance was also computed over the number of letters written on trial 10, and, again, both interval and letters were significant at the .01 level $\left(F^{\prime} s=15.76\right.$ and 17.03, respectively, both with df $3 / 272$ ), while 


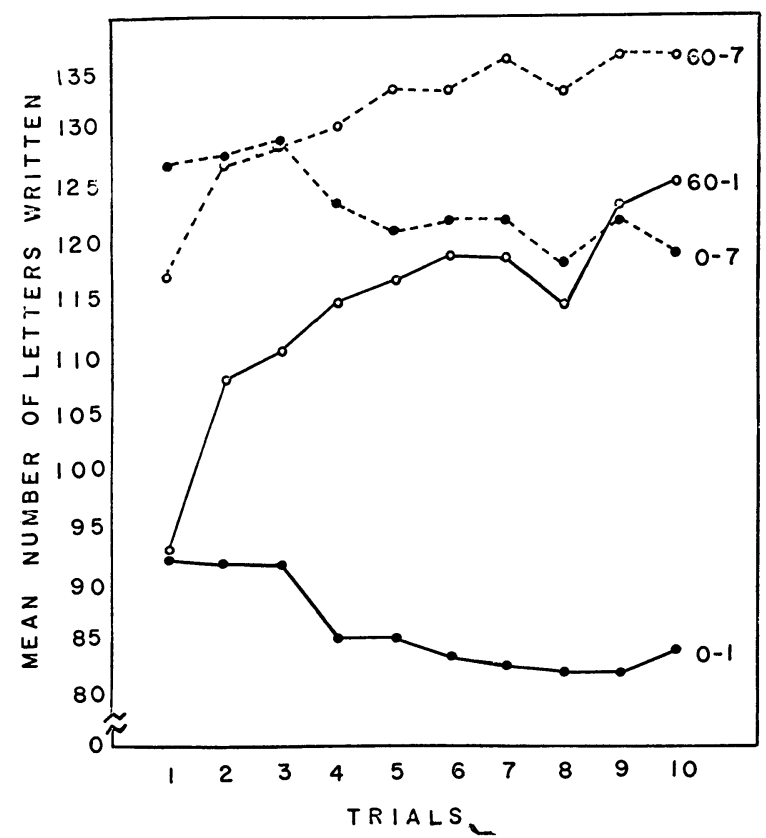

Fig. 1. Mean number of letters written on each trial by groups $0-1,0-7,60-1$, and 60-7.

the interaction was not significant. The analysis of variance over the number of letters written on trial 1 revealed that the greater the number of different letters to be written, the greater the total number of letters written on trial $1(\mathrm{~F}=27.88$; df $3 / 272 ; \mathrm{p}<.01)$.

\section{Diseussion}

It is necessary to conclude that the hypothesis concerning the specificity of $I_{R}$ was not fully supported.
One alternative would be to abandon this hypothesis entirely and try another approach. However, because of the significance of letters as a main effect, especially on the first trial, such an approach might not be completely satisfactory. Another alternative is to retain the idea of specificity and supplement it with additional assumptions. One such assumption might be that $I_{\mathbf{R}}$ builds up to a point beyond which it increases no further; there may be other assumptions. Which, if either, alternative is correct cannot be determined from these data. However, other tests of the specificity hypothesis may be made. For instance, if the hypothesis is correct, it should be possible to find an increase in performance after writing one letter over and over and then switching to another.

There is one final aspect of the data that is worth noting, namely the question as to whether learning occurred. That it did occur in the 60-1 and 60-7 groups is illustrated by the curves in Fig. 1 , and those not shown (60-3 and 60-5) were similar to these. What is being learned? One possibility is that the learning may consist of the overcoming of letter-sequence interference, since we frequently write words and seldom write the alphabet. One way to test this idea is to have Ss write a common word over and over instead of the alphabetical sequence and see if learning occurs under these circumstances.

\section{Reference}

ROBINSON, E.S., \& BILLS, A.G.Two factors in the work decrement. J. exp. Psychol., 1926, 9, 415-443.

\section{Notes}

1. The author would like to thank Dr. Benton J. Underwood for his invaluable contributions throughout all phases of the experiment. 2. Now at the University of Delaware. 